Área Abierta. Revista de comunicación

audiovisual y publicitaria

ISSN: 2530-7592 / ISSNe: 1578-8393

http://dx.doi.org/10.5209/arab.69584

\title{
Nuevas voces en el documental latinoamericano a través del cine ensayo como herramienta para el cambio social
}

\author{
Pablo Calvo de Castroํㅜ María Marcos Ramos ${ }^{2}$
}

Recibido: 19 de mayo de 2020 / Aceptado: 24 de junio de 2020

Resumen. El presente artículo resume las principales conclusiones de una investigación sobre los nuevos lenguajes asociados al ensayo audiovisual encuadrado dentro del cine documental contemporáneo en América Latina. Los resultados están ligados al cambio de rol asumido por los directores respecto a la plasmación de su punto de vista mediante la evolución de la construcción del discurso. Asimismo, se observa una evolución en el papel del espectador, que encuentra un lugar para la reflexión crítica sobre temas concretos de relevancia social en el contexto de América Latina. Se utiliza una metodología cualitativa en la que el análisis fílmico, el análisis histórico, formal y contextual son las técnicas principales. Se puede afirmar que la forma y la estructura narrativa evolucionan con intensidad en la actualidad en el cine documental latinoamericano, un sector de producción que se constituye como un espacio de experimentación formal y discursiva que aporta interesantes novedades a nivel global.

Palabras clave: Documental; América Latina; Ensayo Audiovisual; Denuncia Social; Evolución Narrativa

\section{[en] New Voices in the Latin American Documentary through the Essay Cinema as a Tool for Social Change}

Abstract. This article summarizes the results of an investigation about the new languages associated with audiovisual essays. This audiovisual format is framed within contemporary documentary cinema in Latin America. There is a change in the point of view through the evolution of the construction of discourse. A change of role in the spectator is also observed; the viewer finds a place for critical reflection on concrete issues of social relevance in the Latin American context. We apply a methodology of qualitative analysis - which includes the filmic analysis, the historical, formal and contextual analysis-. We can affirm that the narrative form and structure are currently evolving with intensity in the Latin American documentary cinema, a production sector that advances in a heterogeneous plane. In addition, documentary cinema is constituted as a space for formal and discursive experimentation that brings interesting novelties at a global level.

Key words: Documentary; Latin America; Visual Essay; Social Criticism; Narrative Evolution

Sumario. 1. Introducción y estado de la cuestión. 2. Material y métodos. 3. Análisis y resultados. 4. Discusión y conclusiones. 5. Bibliografía.

\footnotetext{
$1 \quad$ Universidad de Medellín (Colombia)

E-mail: pcavlo@udem.edu.co

ORCID: https://orcid.org/0000-0002-7537-2349

2 Universidad de Salamanca (España)

E-mail: mariamarcos@usal.es

ORCID: https://orcid.org/0000-0003-3764-7177
} 
Cómo citar. Calvo de Castro, P.; Marcos Ramos, María (2020). Nuevas voces en el documental latinoamericano a través del cine ensayo como herramienta para el cambio social. Área Abierta. Revista de comunicación audiovisual y publicitaria 20 (3), 301-315, http://dx.doi.org/10.5209/arab.69584

\section{Introducción y estado de la cuestión}

El cine documental en América Latina ha transitado, a lo largo de toda su historia, por la senda de la denuncia social; esta motivación ha facilitado el desarrollo de nuevas voces que se configuran en herramientas de acción social. La actual investigación se centra en el uso de un formato documental asociado al cine ensayo, representado en cuatro estudios de caso significativos en el cine documental contemporáneo realizado en América Latina: Los herederos (Los herederos, Eugenio Polgovsky, 2008), Patria (Patria, Susana Barriga, 2008), Tren Paraguay (Tren Paraguay, Mauricio Rial Banti, 2011) y Shawantama'ana (Lugar de espera, Yanilú Ojeda, 2012). Estos cuatro títulos se sitúan como referentes dentro de una tendencia innovadora relacionada con el cine ensayo documental, alejado de los postulados más ortodoxos para convertirse en un mecanismo de expresión de las inquietudes de los realizadores a partir del análisis de una realidad social concreta, pues "cine y representación de la realidad pueden llegar a ser dos palabras sinónimas en la medida en la que el cine puede representar la realidad que representa" (Marcos Ramos, 2016: 64).

Este nuevo cine documental combina "todas las tendencias del documental y del arte, en un intento por poner en crisis la realidad representada" (Dufuur, 2010: 336) y asume el ensayo audiovisual desde un discurso reflexivo que "a través de la hibridación de los tipos de discurso posibilitaría la prismática multiplicidad de los modos de confrontación del sujeto, del sujeto ensayista, con el mundo" (Aullón de Haro, 1992: 131). Además, se enmarca como espacio de libertad para la creación narrativa, constituido como formato "de experimentación para la vanguardia cinematográfica [cuya] originalidad radica en la búsqueda de nuevas estructuras formales a través de diversas estrategias narrativas y estéticas, donde los procesos de enunciación han sido uno de los territorios de exploración formal más fructíferos" (Vallejo, 2013: 5). Ofrece una visión de la condición humana que reflexiona "sobre la sociedad y trata de buscar ciertas respuestas sobre problemas éticos en la sociedad actual" (Dufuur, 2010: 336), pues "el fundamento de la narrativa cinematográfica está en dar a conocer situaciones humanas" (Martínez-Salanova, 2010: 48).

En la actualidad, aunque no se pueda hablar del mantenimiento de las vanguardias históricas "sí que nos encontramos con obras cinematográficas [...] cuyo denominador común estaría marcado por el desarrollo de obras al margen de la narrativa convencional, además de unas características estéticas asociadas a la libertad formal, la innovación y la ruptura" (Marcos Ramos, 2018: 35).

Tradicionalmente el documental adquiere los registros miméticos de la realidad, mientras que la ficción asume la diégesis narrativa, interpretando y construyendo la misma. Dejando a un lado las propuestas argumentales, pero sin olvidar la intensa vinculación del documental con la ficción, nos encontramos en un punto en el que "el género ha emprendido un giro hacia el terreno de lo particular y lo personal" (Chanan, 2007b: 72) redefiniendo sus límites y aceptando el punto de vista subjetivo del realizador como camino para la expresión. Analizar las es- 
tructuras narrativas que conforman un documental lleva parejo, inexorablemente, comprender la relación que se establece con las demás artes y por tanto es necesario reflexionar sobre el siglo en el que se produjo (Nogueira, 2010). Así, el vasto campo de experimentación y vanguardia que es el documental desde el nacimiento mismo del cine ha integrado sin dificultad el ensayo audiovisual, en tanto integra una serie de materiales y recursos heterogéneos - comentario, metraje de archivo, entrevistas; intervención del autor- que acaban creando una forma propia" (Weinrichter, 2007: 13). Este elemento de autorreflexión en el cine documental contemporáneo analiza el posicionamiento del autor respecto a la obra y el contexto de esta, "donde el autor se mira a sí mismo o reelabora la imagen ajena desde su punto de vista, dentro del contexto de indefinición del ensayo audiovisual" (García Martínez, 2006: 99). En ese sentido, como apunta Cruz Carvajal (2019: 290), "a través de la forma, el ensayo supera los mecanismos del documental autorreflexivo convertido en autorretrato, del que tanto es deudor, manifestándose mediante una estructura escrita con la materia del medio." En el contexto de los documentales analizados, este proceso tiene lugar imbricado por el enfoque social que permea las creaciones latinoamericanas.

Tiene lugar un proceso en el que "la compresión del otro, la escucha previa a la respuesta no es un acto reflejo y pasivo sino un acto de reapropiación de la voz ajena en un plano de valoraciones, de acentuaciones ideológicas propias, quizás distintas a las previstas por quien las enuncia" (Da Porta, 2013: 52). En este proceso evolutivo "el compromiso del autor con la verdad adquiere una relevancia determinante" (Sánchez Zapatero, 2010: 16-17) que debe ser asumido por el espectador a la hora de dar verosimilitud al relato. Esta característica se puede observar también en el denominado documental reflexivo que "potencia el formato otorgándole al cine documental una condición dialogante entre realizador y espectador" (Dufuur, 2010: 342). Esta instancia retórica implica un involucramiento del público que verifica lo mostrado según "los conocimientos que el espectador posea sobre el universo espacio-temporal en el que vive" (Gaudreault y Jost, 1995: 42).

Estas propuestas personales y subjetivas demuestran una gran "diversidad de estrategias discursivas, que apuntan todas hacia la narración" (Ruffinelli, 2010: 77). Argumento reforzado con las aportaciones de Leonor Arfuch (2002: 99) que, sin circunscribirse al cine documental en concreto, habla de una "multiplicidad en los relatos, susceptibles de enunciación diferente".

Atendiendo al contexto latinoamericano se puede observar cómo ya desde las primeras propuestas del Cine Directo llevadas a cabo en la región a comienzos de la década de los sesenta, y sobre todo con la llegada del Nuevo Cine latinoamericano en sus distintas derivaciones, se plantea el uso del cine documental como herramienta para el cambio (Ortega y Morán, 2003: 43). La forma de codificar el mensaje y la postura asumida por el documentalista respecto al espectador, pero también ante el sujeto filmado, genera susceptibilidades en cuanto a la fiabilidad del documento. Este hecho, unido a la especial idiosincrasia del documental como género cinematográfico, permiten un alto grado de experimentalidad en las obras, algo que favorece la llegada de múltiples voces y modelos narrativos (Gifreu-Castells, 2015: 35).

En este punto es fundamental tener en cuenta dos aspectos que van a condicionar el desarrollo del género. En primer lugar, se debe atender al contexto de producción latinoamericano, en el que las cuestiones vinculadas al concepto de comunicación para el desarrollo propuesto por las Naciones Unidas (2011) cobra gran importancia. Su 
definición más reciente considera "el arte y la ciencia de la comunicación humana ligados a la transformación planeada de la sociedad, desde un estado de pobreza hasta uno de crecimiento socioeconómico dinámico" (Quebral, 2002: 16) lo que favorece la utilización del audiovisual como herramienta para el cambio. En segundo lugar, los aspectos formales están condicionados por una serie de avances técnicos trascendentales para el cine documental. Con la llegada de la tecnología de vídeo en la década de los ochenta, pero sobre todo con la irrupción de las tecnologías digitales de registro y edición a comienzos del siglo XXI (Calvo de Castro, 2018: 16), se configuran nuevos modelos audiovisuales asociados al documental. Destacan las propuestas interactivas que persiguen empoderar a los propios protagonistas de las historias documentadas a partir de la cesión de las herramientas de registro (Moreno Zambrano, 2016: 154), como el proyecto Video nas Aldeias en el que se cede la cámara de vídeo, mucho más sencilla de utilizar que la de cine, a representantes de las comunidades indígenas con las que se está trabajando en territorio amazónico de Brasil (Gallois y Carelli, 1992: 27). En la actualidad, esas iniciativas han derivado en otras que trabajan junto a comunidades de muy diversa índole, conviviendo el modelo interactivo con otro transmedia, un formato que ofrece posibilidades de experimentación casi infinitas. Se llevan a cabo proyectos en distintas áreas, como la de la salud (Reyna, Gaspar y Campos, 2014: 65), la acción política (Restrepo-Hoyos, 2013: 474) o el activismo de la sociedad civil y la lucha social (Gumucio Dagron, 2011: 38) tratando de "alcanzar una relación dialéctica con la realidad" (Guardia, 2011: 136).

Es aquí donde se ubica el ensayo audiovisual dentro del género documental y en América Latina en los últimos años. Las películas ensayísticas, aunque puedan contar con fragmentos narrativos en su interior, "no se rigen habitualmente por la causalidad narrativa sino por la influencia del yo" (García Martínez, 2006: 99). Esta es claramente evaluable en el contexto de creación documental contemporáneo en América Latina y va a situar al ensayo audiovisual dentro del cine documental como una nueva voz.

Si bien el ensayo audiovisual ha estado en constante evolución desde las primeras obras de Benjamin Christensen, Orson Welles o Roberto Rosellini, son cineastas como Ralph Arlyck, Chris Marker, Craig Baldwin o Agnes Varda los que lo desarrollan coincidiendo con los momentos de inflexión generados por los cambios en la técnica antes mencionados y por la constante redefinición que admite la no ficción.

Se pretende, por tanto, indagar sobre las principales características de las nuevas voces en el cine documental latinoamericano. Para ello se analizan las obras de cuatro directores significativos que han utilizado el cine ensayo como herramienta para el cambio social. Con el fin de conocer los elementos distintivos comunes a estos directores, se plantean las siguientes cuestiones o preguntas de investigación: 1) ¿Es el ensayo audiovisual, tomado como modalidad del cine documental, un género que contribuye a la configuración de nuevas voces que tienen por objeto el cambio de diferentes realidades sociales?; 2) ¿Evoluciona la forma narrativa a través del lenguaje y la construcción que aportan estas novedades formales?; y 3) ¿Esta nueva forma narrativa, se distancia, por tanto, de la utilizada tradicionalmente? La respuesta a estas tres cuestiones será el eje sobre el que giren los resultados y las conclusiones del estudio planteado. 


\section{Material y métodos}

Los métodos utilizados en esta investigación de corte cualitativo son, como apunta Flick (2002: 226-227), el análisis fílmico, el análisis histórico y contextual, el decoupage de los aspectos formales y el análisis narrativo aplicado a la idiosincrasia del cine documental. El análisis fílmico es uno de los métodos más utilizados por investigadores al asumir diversos roles, entre los que destacan los "interpretativos, narrativos, teóricos, políticos y metodológicos" (Denzin y Lincoln, 2012: 50). Si bien es cierto que esta técnica ha sido profusamente utilizada en el campo del cine argumental, en el documental han sido autores como Paulo Antonio Paranaguá (1984, 2003a, 2003b, 2009), Alfonso Gumucio Dagron (2014), Jorge Ruffinelli (2012), Julianne Burton (1990), Michael Chanan (2007a, 2007b) o María Luisa Ortega (2007, 2009, 2010) los que la han utilizado para analizar el documental latinoamericano, sin olvidarnos de referencias como Nichols (1997, 2001, 2003, 2006, 2013), Bordwell, Staiger y Thompson (1997), Aumont (2004) o Breschand (2004) que, ya sea desde una perspectiva teórico-analítica o de revisión histórica, abordan y ponen en valor el cine documental a escala global.

Para este trabajo el documental se considera "una obra artística autónoma, susceptible de engendrar un texto que fundamente sus significaciones sobre estructuras narrativas y sobre bases visuales y sonoras, produciendo así un efecto particular sobre el espectador" (Aumont y Marie, 1990: 18), por lo que el análisis de cada una de sus partes - las cuestiones formales y narrativas y el contexto de producciónpermitirá profundizar en el conjunto. Para realizar esta investigación, se elaboró ficha de análisis ad-hoc en la que se tuvieron en cuenta las propuestas metodológicas de Aumont y Marie (1990), Bordwell, Staiger y Thompson (1997), Montiel (2002), Martínez-Salanova (2010), Cerdán Los Arcos (2015) y Gutiérrez San Miguel (2015).

Siguiendo las aportaciones de Gómez-Tarín (2006 y 2011), han sido objeto de observación y análisis los elementos que forman parte del análisis fílmico: los objetivables -como son el texto y su estructura, el entorno de producción y recepción y los recursos expresivos-; los elementos no objetivables - entre los que se encuentran los recursos narrativos, la enunciación y el punto de vista-; $y$, finalmente, elementos de interpretación y juicio, como son los que realiza el espectador/analista a partir del contexto global y de un juicio crítico.

A partir de las indicaciones de Alejandro Montiel (2002: 34), quien señala que los estudios analíticos han desarrollado su trabajo en torno a tres áreas - "el análisis de la imagen y el sonido o de la representación fílmica, el análisis del relato o de sus estructuras narrativas y el análisis del proceso comunicativo y del espectador" (Montiel, 2002: 34) - esta investigación se ha centrado en el análisis de los aspectos formales, los narrativos — aplicados a la especificidad del cine documental- y los contextuales, teniendo en cuenta que se aplican a los procesos de producción y no de recepción. Se elaboró para cada una de las películas analizadas una ficha de análisis en la que se recogen datos según el planteamiento anteriormente descrito.

Este artículo centra su análisis en cuatro títulos del cine documental latinoamericano, por lo que el análisis del contexto social se considera crucial al entenderse que este género "desempeña una función social de valor incalculable en un espacio público degradado y manipulado por el impulso antidemocrático que gobierna los medios de comunicación de masas" (Chanan, 2007b: 68-69). También es fundamental analizar los aspectos técnicos y formales al estar condicionados por la escasez 
presupuestaria (King, 1994: 107) así como el empleo de reducidos equipos técnicos y humanos. Estos condicionantes son la norma en el género documental y cruciales si se analiza el contexto de producción latinoamericano. No se debe olvidar que forma y contenido, significante y significado, son imprescindibles a la hora de analizar un relato audiovisual pues "los elementos significantes del filme, [...] también poseen una sustancia" (Metz, 2002: 110), ya que delimitan, matizan y condicionan la manera en la que el realizador aborda la historia y por tanto configura el texto que estructura el significado de la película.

Las películas analizadas forman parte de una muestra mayor, que reúne cien títulos de la historia del cine documental en América Latina (1924-2014) en un estudio transversal sobre la idiosincrasia del género en la región.

Para la selección de la muestra general se tuvieron en cuenta los títulos de referencia que aportan Julianne Burton (1990), Paulo Antonio Paranaguá (2003a) y Jorge Ruffinelli (2012) y las propuestas clasificatorias aportadas por tres autores de relevancia en cuanto al estudio del género como son Erik Barnouw (1996), Michael Renov (1993) y Bill Nichols (1997, 2001, 2003, 2006 y 2013). Otro factor que condicionó la selección fue el volumen de producción de los distintos países de América Latina, que concurren con distinto nivel de intensidad y cantidad a la cinematografía de la región (Caballero, 2006: 16), tomando en cuenta que el estudio general aborda el contexto latinoamericano en su totalidad.

De la muestra de análisis de cien títulos se seleccionan cuatro películas por su especial vinculación con el cine ensayo en la región, a través del que se configuran nuevas formas de acción social. Así, los títulos seleccionados fueron Los herederos (Eugenio Polgovsky, 2008, México), Patria (Susana Barriga, 2008, Cuba), Tren Paraguay (Mauricio Rial Banti, 2011, Paraguay-Argentina) y Shawantama'ana, lugar de espera (Yanilú Ojeda, 2012, Venezuela). Cada una con diferente nacionalidad y temática, establecen un patrón a partir del que analizar cómo se desarrollan distintas fórmulas de ensayo audiovisual dentro del cine documental que mantienen un rasgo común, el uso de este formato audiovisual como herramienta para la denuncia social.

\section{Análisis y resultados}

Una de las cuestiones fundamentales halladas es el uso del ensayo audiovisual como formato dentro del cine documental. Implicando la mirada del autor, asume una serie de postulados formales y narrativos novedosos mediante los que aborda una problemática social más o menos general del contexto latinoamericano —el trabajo infantil en México, el olvido de las zonas rurales en Cuba, la desmembración de las zonas rurales de Paraguay mediante la ausencia del ferrocarril y la situación de desigualdad y el proceso de aculturación del pueblo wayuu en Venezuela - En este sentido, uno de los elementos más significativos es la cuestión de la autorreferencialidad, donde el autor se mira a sí mismo o reelabora la imagen ajena desde su punto de vista.

En el cine documental realizado en América Latina hubo que esperar hasta la década de los ochenta para que se comenzaran a valorar las propuestas autorreferenciales (Calvo de Castro y Marcos Ramos, 2018 y Ruffinelli, 2010). Para afrontar una temática determinada y plasmarla en una película, primaba el "interés colectivo antes que, en el individual, [...] vinculado a la noción de que la historia la hacen las masas y no los individuos" (Ruffinelli, 2010: 61) en un contexto condicionado por 
fuertes cambios sociales y la militancia política activa que, en los años sesenta y setenta, tiene lugar en América Latina. En las cuatro películas analizadas se observan sendas estrategias para redefinir el ensayo audiovisual que, inserto en el cine documental, genera nuevas fórmulas de acción social.

En Los herederos (2008) Eugenio Polgovsky centra su mirada hacia la infancia explotada en México para así denunciar una situación de injusticia: la película retrata el trabajo infantil que todavía en el siglo XXI se lleva a cabo en muchas zonas rurales del país afectadas por el subdesarrollo o por la presencia de corporaciones que subcontratan el trabajo de jornaleros por salarios ínfimos, lo que condiciona la supervivencia de muchas familias que requieren la ayuda de sus hijos pequeños para completar unos ingresos mínimos.

El rodaje llevó a Polgovsky a diversas zonas rurales de México durante tres años. En el momento de su exhibición la película generó un intenso debate sobre el trabajo infantil en el país, por lo que fue censurada en distintas instituciones.

Respecto a sus aspectos formales, la película no tiene una división clara en secuencias, sino que se van alternando las distintas localizaciones produciendo breves escenas en las que el espectador asiste a las distintas actividades que realizan los niños, como el trabajo en las plantaciones, buscar leña y agua, trabajar la tierra ayudando a sus familias, fabricar adobe o realizar las tareas del hogar. El tipo de angulación y los movimientos de cámara - derivados del estilo observacional con el que el propio Polgovsky graba-, junto a la alternancia en el montaje de distintos tipos de encuadre que restan valor a la descripción de ubicaciones geográficas concretas y se lo otorgan por completo al trabajo de los niños, contribuyen a reforzar esta indefinición secuencial, en la que el director establece una serie de diálogos visuales, como el que se produce entre la construcción de la casa y el molino de maíz, entre la arena y la harina. Este juego visual será utilizado por Polgovsky a lo largo de la película, construyendo así micro-diálogos en un relato que prescinde de la narración en off y de la música.

El director compone una estructura narrativa que otorga por completo la importancia a los niños. Una de las estrategias para lograrlo es tratar a los adultos como personajes anónimos por lo que aparecen en muchas de las escenas, pero siempre de espaldas o con la cara oscurecida por el contraluz con el fin de situarlos en un nivel de importancia secundario respecto a los niños.

El montaje va alternando en cada escena los distintos tipos de plano con los que Eugenio Polgovsky ha registrado cada acción omitiendo la narración en off: mantiene un estilo observacional que permite capturar las imágenes con niños - algo complejo si no se logra una relación de confianza - a partir de la normalización de la convivencia y de las prolongadas estancias con las distintas comunidades y familias documentadas, para así convertir la película en un documento de denuncia de las condiciones de vida de sus protagonistas, los niños sin infancia dedicados por entero a la supervivencia familiar que sin escuela, el trabajo y las obligaciones se convierten en un juego que realizan con el grupo de iguales.

Susana Barriga analiza en Patria (2008) una situación general, ubicando su mirada en los aspectos íntimos y personales de una familia cuya situación es extrapolable a diversos colectivos que habitan las zonas rurales de Cuba. Realiza, así, una reflexión sobre la situación de un grupo familiar del entorno rural cubano y sus precarias condiciones de vida, pero sin hacer una evidente crítica al abandono de las zonas campesinas a favor de los núcleos urbanos, sino desarrollando una mirada 
introspectiva hacia los personajes, lo que permite al espectador la reflexión sobre la realidad social en la que viven.

Aunque se perciben aspectos que denotan que es una película de una autora novel en algunas cuestiones narrativas como la actitud contemplativa frente a los hechos, Susana Barriga demuestra también un magistral uso del encuadre, sobre todo en las escenas localizadas en el interior de la vivienda, donde aparecen numerosos planos en los que la directora sitúa la cámara produciendo composiciones que otorgan gran importancia a las líneas rectas del mobiliario para producir puntos de fuga a través de los que se priorizan elementos y personajes dentro de la escena. Esta estrategia formal se combina de manera constante con el uso de encuadres compuestos por planos cortos, mediante los cuales Barriga fomenta esa sensación de aislamiento de los personajes justificada por la propia orografía del entorno y por la actitud y la falta de relación de los miembros de la familia que protagoniza la película. Destaca también el uso de la luz natural en muchas de los planos recurso en el interior de la vivienda, donde se combina la luz del sol que entra por las rendijas de la cabaña con el humo de la cocina de leña.

Pero, sobre todo, resalta la potencia dramática que desprende la banda sonora, que prescinde de todo artificio para, tras la breve introducción inicial de la voz en off, establecer mediante el sonido ambiente una sensación de vacío en la ausencia de toda conversación entre los miembros de la familia, tanto en el trabajo de reparación del camino como en su estancia en la vivienda. Sin diálogo ni texto, la cámara transita por los rostros y las miradas perdidas de los personajes, por la falta de interacción verbal y por el sonido de sus actividades — o del viento y la lluvia - en el contexto de incomunicación en el que viven. Esta atmósfera contemplativa, construida por Barriga, permite al espectador reflexionar sobre temas que trascienden a los datos generales sobre una realidad social y ponen el foco sobre cuestiones íntimas que no son otra cosa que las consecuencias, plasmadas a nivel individual, de una situación de aislamiento generada por la desigualdad entre el campo y ciudad en Cuba.

En Tren Paraguay (2011) el director persigue la recuperación de una infraestructura ferroviaria abandonada por la administración en Paraguay y lo hace a través de la memoria de los habitantes de la zona. Rial Banti realiza un espléndido ensayo documental sobre la ausencia destacando por el original tratamiento de la memoria (López Petzoldt, 2017: 19), a través del recuerdo del tren, "como si el documental mismo fuera un tren en marcha. [...] Es también un homenaje a la memoria afectiva de la colectividad" (Ruffinelli, 2012: 264).

Mauricio Rial Banti escapa de la reconstrucción histórica, pues se aleja del tono periodístico como herramienta para la descripción de hechos concretos para sumergirse en un ambiente poético elaborado a partir del cuidado uso de la imagen y del sonido. La iluminación natural experimenta un proceso de evolución a lo largo de la película, transitando desde la luminosidad de las primeras imágenes hacia tomas con nubes, ensombrecidas por la luz más tenue, fría y apagada que aportan los días de lluvia. Este recurso se inserta con gran sutileza y contribuye a modular el tono narrativo que va desarrollando el director, mediante el que conduce al espectador desde un plano descriptivo hacia otro reflexivo sobre la temática tratada ofreciendo su punto de vista sin establecer injerencias.

Estructuralmente, el documental adopta una forma cinematográfica en la que la fotografía es uno de los elementos formales más destacables: combina los planos detalle de locomotoras antiguas y estaciones abandonadas con los planos generales 
de paisajes a través de un ritmo sintético en donde los testimonios de las personas entrevistadas, convertidos en voz en off, anteceden permanentemente a unas imágenes dotadas de singular belleza. Mauricio Rial Banti realiza constantes cambios de foco en el registro de los testimonios y en las tomas de recurso. Esta estrategia, unida a la falta de profundidad de campo, contribuye a elevar el nivel estético de las imágenes. Se observa, además, el uso constante de movimientos de seguimiento, el travelling subjetivo que emula el tránsito de un tren por las vías abandonadas y panorámicas de acompañamiento. Acompañados del sonido ambiente introducido en la sala de montaje en la banda sonora, estos movimientos forman parte de la recreación visual del pasado, siempre incorporados a la visión de quién los recuerda. El montaje otorga gran importancia al factor visual de la película. Los testimonios se combinan con una gran variedad de imágenes y con una elaborada banda sonora que emula los sonidos de épocas pasadas mientras se muestran elementos abandonados en la actualidad. Con todos estos recursos, Rial Banti sitúa la fotografía como uno de sus elementos formales más destacables, pero es la banda sonora el aspecto fundamental de la narrativa de la película: complementa las imágenes de las estaciones vacías con el sonido ambiente de las locomotoras y la actividad de la estación, capturado en otros momentos e insertado en el montaje, emulando así el tiempo pasado sin tener que recurrir a la recreación visual, a la imagen de archivo o a la voz en off de un narrador omnisciente.

Igual que ocurre con las dos películas anteriores, Tren Paraguay (2011) no tiene secuencias definidas, sino que va combinando los distintos testimonios de las personas que de alguna manera vincularon su vida al tren en estaciones hoy abandonadas, sustentando estas la narración en la que se concatenan las experiencias de los jóvenes que acudían a la llegada del tren como si fuera una fiesta.

Por último, en Shawantama'ana (Lugar de espera) (2012) Yanilú Ojeda reivindica la preservación de una cultura indígena a través del respeto a sus costumbres en un contexto de fuerte aculturación sin negar el acceso al desarrollo. La película, a diferencia de El terminal de pasajeros (2006) dirigida también por Yanilú Ojeda y que indaga sobre una temática similar desde un estilo observacional, cambia el punto de vista al otorgar el protagonismo de la narración a los propios indígenas, pasando de observarlos a integrarlos, alejándose de la descripción y utilizando propuestas más reflexivas. Si bien tanto El terminal de pasajeros (2006) como la película analizada, "ofrecen una mirada antropológica" (Carreño, 2012: 204) sobre los intercambios culturales entre el pueblo wayuu y la población colona, en el caso de Shawantama 'ana, lugar de espera (2012), la directora prescinde de la narración en off otorgando el peso de la conducción argumental a sus protagonistas, que se convierten en los narradores de la historia del lugar, de la etimología del nombre con el que llaman a la estación - Shawantama'ana-, de las primeras ubicaciones de la terminal y de los avatares sufridos hasta poder establecerse en un lugar permanente y con identidad propia.

En la sucesión de las tres grandes secuencias en las que se divide la película se produce un punto de inflexión en la vida de los wayuu con la llegada del camión, el medio de transporte por excelencia en La Guajira, ya que pasan de realizar largos trayectos a pie en un territorio semidesértico y falto de toda infraestructura a poder desplazarse en este medio de transporte colectivo. Este es el punto de partida de los procesos de hibridación cultural y aculturación que vive la población wayuu en su relación con la sociedad de consumo, que son descritos en varios momentos del do- 
cumental, como en la escena de la inspección en busca de material de contrabando - o comercio informal - por parte de las autoridades o en el uso de artículos tecnológicos como el teléfono móvil.

En el caso del contrabando, estas prácticas son ancestrales en los wayuu, que han asumido un modelo económico y comercial paralelo al establecido por los estados de Colombia y Venezuela, entre los que dividen su territorio. En el caso de la tecnología, su uso es claramente operativo, aunque este tipo de vinculaciones con la sociedad de consumo acaban mellando la identidad cultural de la colectividad, que asume modelos occidentalizados y alienantes. Ojeda representa este hecho sin tomar partido, contraponiendo los elementos de occidentalización con otros que representan la identidad cultural, pero definiendo una interferencia, no de la película o del rodaje, sino del propio y mal llamado desarrollo. La directora establece un itinerario narrativo que transgrede los límites de la observación y de la enunciación de la historia, empodera a sus protagonistas y transita de manera zigzagueante por la constante relación del pueblo wayuu con el modelo occidental que pagan el precio de la pérdida de identidad cultural mientras la estructura social los sitúa en un plano de exclusión.

La directora utiliza el desenfoque mediante movimientos de lente como elemento de transición entre planos recurso y la combinación de planos generales, de conjunto, medios y planos detalle para acercarse a las distintas localizaciones. El movimiento interno es variable en función de la localización de cada escena y cuando es escaso da lugar a imágenes de naturaleza introspectiva en las zonas rurales, muy poco pobladas, en las que los encuadres incluyen los camiones o las familias de indígenas caminando por el desierto. Se torna más intenso tanto en los planos registrados en la terminal de pasajeros como en el resto de las localizaciones de la ciudad de Maracaibo. Con esta dicotomía contribuye a establecer dos ambientes con dos ritmos narrativos y dos tonos visuales diferenciados. El montaje combina el registro directo de tomas de recurso con el testimonio derivado de entrevistas, que en numerosas ocasiones están superpuestas con las tomas de recurso. Utiliza la música y la disolución mediante fundido a negro como elementos de transición. La banda sonora está compuesta por el sonido directo, varios testimonios convertidos en narración en off y otros representados con entrevistas con un formato más ortodoxo o canónico. $\mathrm{Si}$ bien Ojeda utiliza los mimbres de inserción y empoderamiento del discurso indígena que ya plantearan Dominique Gallois y Vincent Carelli (1992) en A arca dos Zo'é (1993), los redefine para superar la orientación puramente indigenista e introducir la cuestión de la aculturación como elemento central de la pérdida de derechos sociales en el plano de desigualdad al que se ven sometidos.

\section{Discusión y conclusiones}

Con todo lo analizado, se puede concluir, en torno a la verificación de la primera pregunta de investigación, que el ensayo audiovisual, inserto dentro del cine documental, asume diversas formas que canalizan la mirada y la inquietud del autor sobre un determinado tema para generar novedosos y variados lenguajes. Estas nuevas estrategias tratan de generar en el espectador una actitud crítica a través de la reflexión sobre determinados hechos sociales que se observa en la redefinición de la mirada antropológica de Yanilú Ojeda en Shawantama'ana, lugar de espera (2012) o en el 
diálogo establecido entre imagen y sonido por Mauricio Rial Banti en Tren Paraguay (2011). Rial Banti propone al espectador un contexto audiovisual que invita a la reflexión crítica mediante la combinación de elementos estéticos con una fuerte carga simbólica. Aunque se debe admitir que el director también utiliza estrategias más ortodoxas, como los testimonios de los entrevistados, son los aspectos formales, referidos a la imagen y al sonido, los que decantan la balanza hacia estas nuevas configuraciones.

La segunda cuestión se verificó al constatar la aparición de diversos elementos que ofrecen evoluciones claras en el documental tradicional, con la desaparición, por ejemplo, de la voz en off. Un hecho que, lejos de atenuar la presencia de la mirada personal del realizador, contribuye a reconfigurar la construcción del discurso de este, otorgando mayor peso a los testimonios de los protagonistas tanto en lo visual como en lo sonoro y estableciéndose, así como contrapunto respecto al cine documental tradicional. En lo referido a Tren Paraguay (2011), cabe añadir que, en este caso concreto, se sustituye la voz en off por un complejo montaje sonoro que evoca imágenes del pasado sin necesidad de utilizar materiales de archivo histórico, sino estableciendo un diálogo con la imagen actual, que captura las ruinas de las estaciones y antiguas máquinas oxidadas y abandonas.

La supresión de la voz en off tiene una especial relevancia tanto en Los herederos (2008) como en Patria (2008), de tal manera que la ausencia de una narración implica otorgarle mayor importancia al testimonio visual, articulado en cada caso de forma diferente. En Los herederos (2008) Polgovsky utiliza un estilo observacional que aumenta la carga dramática de la imagen ya que la falta de información textual, ya sea hablada o escrita, implica aislar a los protagonistas sin poder ubicarlos en un territorio concreto. Los distintos grupos de niños que aparecen en la película representan una realidad extrapolable a muchos lugares de México y América Latina. En el caso de Patria (2008), Susana Barriga utiliza la convergencia entre la ausencia de narración y la fuerte carga dramática de la imagen, derivada de una cuidada composición visual y la actitud de los personajes ante la cámara para articular su posicionamiento ante la realidad de las zonas rurales de Cuba. En esta ocasión el recorrido es introspectivo, ya que la mirada de la directora viaja desde una realidad social hacia la intimidad de los individuos que representan dicha realidad.

La supresión de la voz en off tiene una especial relevancia tanto en Los herederos (2008) como en Patria (2008) de tal manera que la ausencia de una narración implica otorgarle mayor importancia al testimonio visual, articulado en cada caso de forma diferente. En Los herederos (2008) Polgovsky utiliza un estilo observacional que aumenta la carga dramática de la imagen ya que la falta de información textual, ya sea hablada o escrita, implica aislar a los protagonistas sin poder ubicarlos en un territorio concreto. Los distintos grupos de niños que aparecen en la película representan una realidad extrapolable a muchos lugares de México y América Latina. En el caso de Patria (2008), Susana Barriga utiliza la convergencia entre la ausencia de narración y la fuerte carga dramática de la imagen, derivada de una cuidada composición visual y la actitud de los personajes ante la cámara para articular su posicionamiento ante la realidad de las zonas rurales de Cuba. En esta ocasión el recorrido es introspectivo, ya que la mirada de la directora viaja desde una realidad social hacia la intimidad de los individuos que representan dicha realidad.

La última de las preguntas de investigación planteadas es contestada al comprobar cómo los elementos narrativos que configuran este estilo cinematográfico se apoyan 
en la ausencia de secuencias definidas que permitan compartimentar la evolución de la historia, reduciendo su fuerza descriptiva y aumentando la reflexiva. Esto hace patente la diversidad de opciones narrativas que aporta el ensayo audiovisual como herramienta para el cambio social. Se puede apreciar que la falta de estructuración narrativa a la manera clásica configura modelos distintos en cada caso que escapan, en este momento de la evolución del cine documental, a fórmulas prefijadas, lo que implica un constante replanteamiento de las estrategias narrativas y discursivas. Es por ello que la presente línea analítica ofrece grandes posibilidades para investigaciones futuras al ser el ensayo audiovisual, especialmente en su conexión con el formato documental, un género cinematográfico en constante evolución en el que además son los propios realizadores los que llevan a cabo constantes replanteamientos teóricos sobre forma y contenido.

Tras todo lo visto, se puede concluir que las películas analizadas como exponentes del cine ensayo inserto dentro del cine documental en el contexto latinoamericano, tienen una serie de rasgos comunes. Más allá de la pertenencia a un contexto regional con sus particularidades - que motivan a los directores para desarrollar sus proyectos--, las películas analizadas sitúan el ensayo audiovisual dentro del cine documental en convivencia con distintos modelos de experimentación audiovisual, como son el documental interactivo o el audiovisual transmedia, utilizados con profusión como herramienta de empoderamiento de colectivos y de comunidades que hoy en día no se circunscriben a propuestas indigenistas o de militancia política sino que amplían su espectro a una amplia variedad de reivindicaciones de la sociedad civil. En este sentido, cabe añadir que el ensayo audiovisual ubicado en este contexto concreto genera nuevas voces para el cine documental y para el audiovisual en general, desde la plasmación de historias y temáticas que pueden estar alejadas entre sí, pero que se conectan por la motivación común de referenciar realidades sociales que es necesario cambiar mediante el desarrollo de una actitud crítica por parte del espectador a partir de la información configurada a través de la mirada de los directores en un formato audiovisual que goza de gran madurez en la actualidad.

En todo caso, la presente investigación no pretende ser concluyente al haber analizado una muestra muy pequeña, pero tiene la ambición de aportar reflexiones en torno a este formato documental, que ha evolucionado a partir de la convergencia entre el ensayo audiovisual y el abordaje de distintas realidades sociales en un momento en el que el cine documental trasciende a cuestionamientos en torno a la autorreflexión y los roles que asumen narrador y espectador, en un contexto de total libertad creativa e intensa implicación social.

A fin de profundizar más en las conclusiones detectadas, se pretende ampliar el número de películas e indagar en este aspecto también dentro del cine argumental. Esto permitirá enriquecer la metodología en torno al análisis de relatos fílmicos, lo cual se espera que aporte resultados más completos al estado de la ciencia en este ámbito de estudio.

\section{Bibliografía}

Arfuch, L. (2002). El espacio biográfico. Dilemas de la subjetividad contemporánea. Buenos Aires: Fondo de Cultura Económica. 
Aullón de Haro, P. (1992). Teoría del ensayo. Madrid: Verbum.

Aumont, J. (2004). Las teorías de los cineastas: la concepción del cine de los grandes directores. Madrid: Paidós Ibérica.

Aumont, J. y Marie, M. (1990). Análisis del film. Barcelona: Paidós.

Barnouw, E. (1996). El documental, historia y estilo. Barcelona: Gedisa.

Bordwell, D., Staiger, J. \& Thompson, K. (1997). El cine clásico de Hollywood. Estilo cinematográfico y modo de producción hasta 1960. Barcelona: Paidós.

Burton, J. (1990). The Social Documentary in Latin America. Pittsburg: PA U. Of Pittsburg.

Caballero, R. (2006). Producción, coproducción e intercambio de cine entre España, América Latina y el Caribe. Avances de investigación 5. Madrid: Fundación Carolina CeALCI.

Calvo de Castro, P. (2018). "La evolución del cine etnográfico en el documental latinoamericano". Cine Documental, 17, 1-23. Recuperado de https://goo.gl/yNdpje (Fecha de acceso: 10/02/2020).

Calvo de Castro, P. \& Marcos Ramos, M. (2018). "La autorreferencialidad en el cine documental en América latina". Vivat Academia. Revista de Comunicación, 145, 113-128. doi: http://doi.org/10.15178/va.2018.145.113-128 Recuperado de http://www.vivatacademia. net/index.php/vivat/article/view/1100 (Fecha de acceso: 10/02/2020).

Carreño, V. (2012). "Terminales, pasajeros y resignificación de los lugares en Maracaibo: el cine documental de Yanilú Ojeda". Anales del IAA, 42, 2, 203-222. Recuperado de https:// goo.gl/K1Ce87 (Fecha de acceso: 15/02/2020).

Cerdán Los Arcos, J. (2015). “Un lugar ético para las imágenes documentales (en el contexto de las ciencias sociales)". En Vanessa Fernández Guerra (Coord.). Revisitando el documental; de Flaherty al webdoc, Cuadernos Artesanos de Comunicación. N. 83 La Laguna (Tenerife): Latina, 17-32. Recuperado de https://goo.gl/QWM3BR (Fecha de acceso: 18/01/2020).

Chanan, M. (2007a). The Politics of Documentary. London: British Film Institute.

Chanan, M. (2007b). "El documental en el espacio público". Archivos de la filmoteca: Revista de estudios históricos sobre la imagen, 57, 68-89. Recuperado de https://goo.gl/3HhGZf (Fecha de acceso: 10/02/2020).

Cruz Carvajal, I. (2019). "Hacia una gramática del ensayo audiovisual”, en Francisco Sierra Caballeo y Jordi Alberich Pascual (eds.). Epistemología de la comunicación y cultura digital: Retos emergentes. Granada: Universidad de Granada. 285-295.

Da Porta, E. (2013). "Pensar las subjetividades contemporáneas: algunas contribuciones de Mijail Bajtín". Estudios semióticos, 9, 1, 47-54. Recuperado de https://goo.gl/YzFxu1 (Fecha de acceso: 14/03/2020).

Denzin, N. K. \& Lincoln, Y. (2012). "La investigación cualitativa como disciplina y como práctica”. En Norman K. Denzin \& Yvonna Lincoln (Coords.). Manual de investigación cualitativa. Barcelona: Gedisa, 43-102.

Dufuur, L. (2010). "Tendencias actuales del cine documental". FRAME, 6, 312-349. Recuperado de https://goo.gl/UxHkAP (Fecha de acceso: 10/02/2020).

Flick, U. (2002). An introduction to Qualitative Methodology. Chicago: Markham.

Gallois, D. \& Carelli, V. (1992). "Vídeo nas aldeias: a experiência Waiãpi”. Cadernos de Campo 2 (2), 25-36. Recuperado de https://goo.gl/Ks8Lai (Fecha de acceso: 15/02/2020).

García Martínez, A. N. (2006). "La imagen que piensa. Hacia una definición del ensayo audiovisual”. Comunicación y Sociedad, 19 (2), 75-105. Recuperado de https://goo.gl/7aMV5V (Fecha de acceso: 10/02/2020).

Gaudreault, A. \& Jost, F. (1995). El relato cinematográfico. Barcelona: Paidós. 
Gifreu-Castells, A. (2015). "Evolución del concepto de no ficción. Aproximación a tres formas de expresión narrativa". Obra Digital, 8, 14-39. Recuperado de https://goo.gl/pGQstF. (Fecha de acceso: 10/03/2020).

Gómez-Tarín, F. J. (2006). El Análisis de un texto fílmico. Castellón: Beira Interior.

Gómez-Tarín, F. J. (2011). Elementos de Narrativa Audiovisual. Expresión y narración. Santander: Shangrila.

Guardia, I. (2011). "El documental de intervención y su relación con la realidad histórica. Variaciones en el tiempo". Fotocinema. Revista cientifica de cine y fotografía, 2, 113-139. Recuperado de https://goo.gl/Nkh3Fz (Fecha de acceso: 14/03/2020).

Gumucio Dagron, A. (2011). "Comunicación para el cambio social: clave del desarrollo participativo”. Signo y Pensamiento, 30 (58), 26-39. Recuperado de https://goo.gl/a1GKeE. (Fecha de acceso: 10/02/2020).

Gumucio Dagron, A. (2014). El cine comunitario en América Latina y el Caribe. Bogotá: Fundación Friedrich Ebert. Recuperado de https://goo.gl/9sf7je (Fecha de acceso: 24/02/2020).

Gutiérrez San Miguel, B. (2015). "Estudio evolutivo del lenguaje narrativo, desde los primeros documentales a los transmedia”. En Vanessa Fernández Guerra (Ed.), Revisitando el documental; de Flaherty al webdoc. Cuadernos Artesanos de Comunicación. $83 \mathrm{La}$ Laguna (Tenerife): Latina, 207-244. Recuperado de: https://goo.gl/KiEXWz. (Fecha de acceso: 10/02/2020).

López Petzoldt, B. (2017). "Voces de la memoria comunicativa en el cine. Profesión cinero (2007) y Tren Paraguay (2011)". Iberoamericana, 17 (65), 17-44. Recuperado de https:// goo.gl/jdtVGD. (Fecha de acceso: 10/02/2020).

Marcos Ramos, M. (2016). "El reflejo de la sociedad franquista en el cine de Juan Antonio Bardem: Muerte de un ciclista (1955) y Calle Mayor (1956)". Revista Observatório, 2, 3, 62-86. Doi: https://goo.gl/s417Uc (Fecha de acceso: 10/02/2020).

Marcos Ramos, M. (2018). “Arriluce, un proyecto de cine de vanguardias”. En Luís Martínez-Falero, José Antonio Pérez Bowie \& Keith Gregor (Eds.). Estudios de Literatura. Vol. 1. Las Artes de la vanguardia Literaria. Madrid: Selgyc, 34-44.

Martínez-Salanova Sánchez, E. (2010). "Los sistemas educativos en la memoria heterodoxa del cine europeo". Comunicar, 35, 1134-3478.

Montiel, A. (2002). El desfile y la quietud. Análisis filmico versus Historia del Cine. Valencia: Generalitat Valenciana.

Moreno Zambrano, V. (2016). “Aproximación al potencial colaborativo de la narrativa documental interactiva en los procesos de cambio social". Cultura, lenguaje y representación, 15, 153-169. DOI: http://dx.doi.org/10.6035/clr.2016.15.10 (Fecha de acceso: 10/02/2020).

Nichols, B. (1997). La representación de la realidad, cuestiones y conceptos sobre el documental. Barcelona: Paidós.

Nichols, B. (2001). "Los documentales y el modernismo: 1919-1939". Comunicación y Sociedad, XIV, 2, 7 1-91. Recuperado de https://goo.gl/p4phPS. (Fecha de acceso: 10/03/2020).

Nichols, B. (2003). "El documental performativo". Postverité, 197-221.

Nichols, B. (2006). “Cuestiones de ética y cine documental”. En Josep Maria Catalá \& Josetxo Cerdán (Eds.). Después de lo real. Valencia: Archivos de la filmoteca, 29-45. Recuperado de https://goo.gl/oqhsQs. (Fecha de acceso: 10/02/2020).

Nichols, B. (2013). Introducción al documental. México DF: UNAM.

Nogueira, M. E. (2010). "Understanding Cinema: the Avant-gardes and the Construction of 
Film Discourse". Comunicar, 35, 43-51. Recuperado de https://goo.gl/vJr1mK (Fecha de acceso: 10/02/2020).

Ortega, M. L. (2007). "De memorias y olvidos. El documental latinoamericano contemporáneo". Cuadernos hispanoamericanos, 679, 19-27.

Ortega, M. L. (2009). "De la certeza a la incertidumbre: collage documental y discurso político en América Latina”. En Sonia García López y Laura Gómez Vaquero (Eds.). Piedra papel y tijera: el collage en el cine documental. Madrid: Ocho y Medio, 101-138. Recuperado de https://goo.gl/WqanWY. (Fecha de acceso: 13/03/2020).

Ortega, M. L. (2010). "Nuevos tropos en el documental latinoamericano: subjetividad, memoria y representación”. En Weinrichter (Ed.). El documentalismo en el SXX. San Sebastián: Festival de cine de San Sebastián, 77-99. Recuperado de https://goo.gl/QggDwL. (Fecha de acceso: 10/02/2020).

Ortega, M. L. \& Morán, A. (2003). "Imaginarios del desarrollo: un cruce de miradas entre las teorías del cambio social y el cine documental en América Latina”. Secuencias. Revista de historia del cine, 18, 33-48

Paranaguá, P. A. (1984). O Cinema na América Latina. Porto Alegre: L\&PM Editores.

Paranaguá, P. A. (2003a). Cine documental en América Latina. Madrid: Cátedra.

Paranaguá, P. A. (2003b). Tradición y modernidad en el cine documental en América Latina. Bogotá: Fondo de Cultura Económica.

Paranaguá, P. A. (2009). Miradas desinhibidas. El nuevo documental latinoamericano. Madrid: SECC.

Programa de las Naciones Unidas para el Desarrollo. (2011). Comunicación para el desarrollo. Fortaleciendo la eficacia de las Naciones Unidas. Recuperado de https:/goo.gl/ QkLq2b (Fecha de acceso: 10/03/2020).

Renov, M. (1993). Theorizing Documentary. New York: Routledge.

Quebral, N. (2002). Reflectios on development communication, 25 years after. Los Baños: UBLP College of Development Communication.

Restrepo-Hoyos, P. (2013). "El documental intercultural como herramienta política: bases teóricas y metodológicas a partir de dos estudios de caso". Palabra Clave, 16(2), 470490. Recuperado de https://goo.gl/BReE6C (Fecha de acceso: 14/03/2020).

Reyna, L. A., Gaspar, B. L. \& Campos, M. (2014). "El cine y las representaciones culturales cotidianas como herramientas para la promoción de la salud". Salud y Sociedad Uptc 1(2), 61-66. Recuperado de https://goo.gl/54p2nv. (Fecha de acceso: 10/02/2020).

Ruffinelli, J. (2010). "Yo es/soy el otro. Variantes del documental subjetivo o personal". Acta sociológica, 53, 59-81. Recuperado de https://goo.gl/zYkHft (Fecha de acceso: 10/02/2020).

Ruffinelli, J. (2012). América Latina en 130 documentales. Santiago de Chile: Uqbar Editores.

Sánchez Zapatero, J. (2010). “Autobiografía y pacto autobiográfico revisión crítica de las últimas aportaciones teóricas en la bibliografía científica hispánica”. Ogigia: Revista electrónica de estudios hispánicos, 7, 5-17. Recuperado de https://goo.gl/M2NJdB (Fecha de acceso: 14/03/2020).

Vallejo Vallejo, A. (2013). "Narrativas documentales contemporáneas. De la mostración a la enunciación”. Cine documental, 7. Recuperado de https://goo.gl/w9E5AB. (Fecha de acceso: 10/02/2020).

Weinrichter, A. (2007). "Un concepto fugitivo. Notas sobre el film-ensayo", en Christa Blümlinger y Antonio Weinrichter (eds.), La forma que piensa. Tentativas en torno al cine-ensayo. Pamplona: Fondo de publicaciones del Gobierno de Navarra. 18-48. 